\title{
Influência do complexo flúor-xilitol no controle da placa dentária e do sangramento gengival em pacientes herbiátricos com aparelho ortodôntico fixo*
}

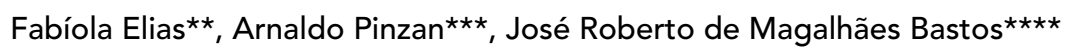

Resumo

Objetivo: avaliar os efeitos de um dentifrício contendo flúor/xilitol na redução da adesão da placa à estrutura dentária, bem como no índice de sangramento gengival, em portadores de aparelho ortodôntico fixo. Metodologia: foram avaliados 22 jovens, com idade entre 14 e 17 anos. Após a quantificação inicial dos índices, os jovens receberam instruções de escovação e começaram a utilizar somente os dentifrícios da pesquisa. Houve uma divisão aleatória da amostra em dois grupos (A e B). Na primeira semana todos utilizaram um dentifrício padrão e a partir da segunda semana os jovens do grupo A receberam um dentifrício contendo flúor, enquanto os do grupo B receberam um dentifrício contendo o complexo flúor-xilitol, que utilizaram durante vinte e oito dias, quando foram novamente avaliados (T1). Para a segunda fase (T2) houve inversão dos dentifrícios. Resultados: foram comparados os resultados intra-grupo e nos dois grupos houve redução estatisticamente significante entre as fases inicial e T1, inicial e T2 e entre T1 e T2. Já na comparação entre os grupos não houve diferença estatisticamente significante entre eles, embora o dentifrício contendo flúor/xilitol tenha proporcionado uma porcentagem de redução do índice de sangramento gengival maior que o dentifrício contendo apenas o fluoreto de sódio, principalmente entre as fases inicial e T2, onde a redução no grupo A foi de $90,13 \%$ e no grupo B foi de $78,84 \%$. Conclusão: a utilização de dentifrícios contendo flúor e xilitol, associada à instrução e motivação, parece ser um recurso bastante promissor para a manutenção da saúde bucal nos pacientes ortodônticos.

Palavras-chave: Aparelho ortodôntico fixo. Dentifrício. Xilitol. Paciente herbiátrico. Placa dentária. Sangramento gengival.

* Resumo da Dissertação (Mestrado) apresentada à Faculdade de Odontologia de Bauru - FOB - USP.

** Especialista em Ortodontia e Ortopedia Facial pela Fundação Bauruense de Estudos Odontológicos - Bauru -SP. Mestre em Odontologia, área Odontologia em Saúde Coletiva pela Faculdade de Odontologia de Bauru-USP. Professora Assistente da Disciplina de Ortodontia da Universidade do Sagrado Coração - Bauru-SP.

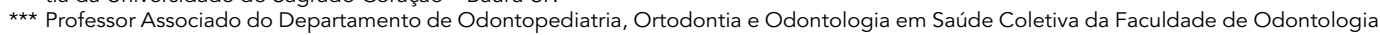
de Bauru -USP.

**** Professor Titular do Departamento de Odontopediatria, Ortodontia e Odontologia em Saúde Coletiva da Faculdade de Odontologia de Bauru -USP. 


\section{INTRODUÇÃO}

A Ortodontia é o ramo da Odontologia que visa à prevenção, à interceptação e à correção das alterações que envolvem os dentes e suas bases ósseas. Para possibilitar a intervenção das más oclusões, o ortodontista, na maioria das vezes, precisa usar como recurso os mais diversos tipos de aparelhos fixos e/ou removíveis, que podem proporcionar alterações na saúde bucal ${ }^{2,13,22,37,42,51,53,85,86}$. Existem, na literatura, diversos trabalhos enfocando a relação entre a instalação do aparelho ortodôntico fixo corretivo e o aumento da retenção de placa dentária ${ }^{42}$, que pode ocasionar um aumento na tendência de cárie durante esse tratamento $^{2,37,51,53,85}$, maiores índices de inflamação gengival ${ }^{13,22,86}$ e de sangramento gengival ${ }^{41}$.

Sendo assim, tão importante quanto prevenir, interceptar e corrigir problemas referentes ao alinhamento dentário e crescimento ósseo é proporcionar, aos pacientes submetidos ao tratamento ortodôntico, a manutenção da sua saúde bucal como um todo, evitando que a placa dentária cause manchas brancas ${ }^{62}$ e gengivites, que poderão se agravar, ocasionando cárie ${ }^{2}$ e doença periodontal ${ }^{13}$.

Por este motivo, diversos estudos vêm sendo realizados, com o intuito de encontrar métodos preventivos, químicos ou mecânicos, capazes de diminuir os efeitos indesejáveis da utilização de aparelhagem ortodôntica ${ }^{81}$.

Dentre os métodos preventivos utilizados no controle da placa dentária em pacientes ortodônticos destaca-se a necessidade da remoção mecânica que, para ser bem executada, depende da instrução de higiene bucal ${ }^{10,13,67,81}$ e da motivação do paciente $^{6,10,67,81}$, que podem ser feitos pelos controles periódicos sobre as condições de higiene bucal, com o auxílio de reveladores de placa dentária ${ }^{10}$ e nos casos mais graves, utilizando-se gravuras que mostrem as possíveis conseqüências do descuido com a escovação dentária, tal como dentes manchados e casos sérios de gengivite ${ }^{36}$.

A limpeza mecânica dos dentes pela escovação é considerada como sendo um método eficaz no controle da placa dentária, entretanto existe uma grande dificuldade em se atingir bons níveis de higiene mecânica em pacientes ortodônticos ${ }^{60}$. Por este motivo, diversos autores propuseram o controle químico da placa dentária para esses pacientes $^{60,81}$. O método químico de controle de cárie mais conhecido e eficaz é a utilização de produtos contendo flúor ${ }^{14}$. Porém, a utilização desses produtos é eficaz na diminuição do risco de cárie ${ }^{15}$ quando associada à escovação dentária ${ }^{5,19}$, na prevenção da desmineralização do esmalte $e^{20,33,82}$ e nos processos de remineralização de manchas bran$\operatorname{cas}^{18,33}$, mas não é capaz de reduzir a retenção da placa na estrutura dentária.

Outra forma mecânica de controlar a desmineralização do esmalte dentário encontrada na literatura é o uso de selantes ${ }^{72}$ ao redor dos braquetes ${ }^{38}$ e das bandas ${ }^{55}$, após a colagem ou cimentação dos mesmos, podendo ser indicado como um material promissor para a prevenção de lesões de cárie na clínica ortodôntica.

Dentre os produtos contendo flúor, utilizados em Ortodontia, podemos destacar o cimento de ionômero de vidro, usado para cimentação de ban$\operatorname{das}^{33,63}$ ou colagem direta de braquetes ${ }^{27,35,83}$, resinas $^{28,34}$ e primers $^{17}$, além de elásticos liberadores de flúor ${ }^{84}$.

O controle químico da placa dentária, com o uso da clorexidina $a^{9,21,23,25,40,60,61,71,73,76}$ ou do cloreto de cetilpiridínio ${ }^{30,40,46,77}$, permite a redução dos índices de placa dentária e sangramento gengival, sendo a clorexidina o método mais eficaz ${ }^{21,24,25,40,61}$, tornando-se o principal elemento químico utilizado para o controle de retenção da placa dentária em pacientes ortodônticos, sempre associada à higienização bucal. Entretanto, o uso prolongado da clorexidina apresenta efeitos colaterais indesejáveis ${ }^{61}$, como manchas nos dentes e na língua, diminuição ou perda do paladar e sensação de queimação da língua ${ }^{76}$.

Este fato nos remete à busca de outros agentes químicos que possam ter os mesmos resultados, porém sem ocasionar tais efeitos colaterais. 
Dentre os métodos químicos de controle da placa dentária na Odontologia, o xilitol vem assumindo um importante papel, por apresentar uma característica peculiar de não fermentação pela maioria das bactérias presentes na cavidade bucal ${ }^{7,54,65}$, tornando a placa dentária menos aderente e de fácil remoção à escovação ${ }^{65}$, podendo ainda atuar como agente de remineralização do esmalte dentário ${ }^{79}$.

O xilitol pode ser empregado como método auxiliar de controle da placa dentária em Odontologia, podendo ser utilizado em gomas de mas$\operatorname{car}^{3,4,7,8,16,47,52,57,58,64,74}$ ou pastilhas ${ }^{11,29}$, enxaguatórios bucais ${ }^{43,44,56}$, dentifrícios ${ }^{31,32,39,45,50,75,78}$ e como estimulantes salivares ${ }^{59}$.

O uso do xilitol em gomas de mascar é o mais difundido e todos os autores $3,4,7,8,16,47,49,52,57,58,64,74$ que estudaram seus efeitos apresentaram bons resultados no controle da placa dentária ${ }^{16,64}$ e na prevenção da cárie ${ }^{3,4,74}$, em todas as idades ${ }^{58}$, havendo ainda a vantagem de uma boa aceitabilidade por crianças com idade entre três e cinco anos ${ }^{8}$.

$\mathrm{Na}$ forma de pastilha, os melhores resultados do xilitol foram encontrados quando foi utilizado na prevenção primária ${ }^{80}$, ou seja, antes dos dentes irromperem na cavidade bucal ${ }^{1,11}$, com a utilização de chupetas com compartimento para a colocação do comprimido e furos no bulbo para a liberação do produto $^{11}$ ou de outros aparelhos que promovem a liberação lenta do xilitol para a saliva ${ }^{1}$.

Sua utilização em enxaguatórios bucais demonstrou que, quando associado ao flúor, o resultado foi mais eficaz na prevenção da cárie, comparado a um enxaguatório contendo apenas o flúor $^{56}$, porém nem sempre este resultado foi significativo ${ }^{43,44}$.

Quanto ao uso do xilitol em dentifrícios, a concentração do mesmo interferiu nos resulta$\operatorname{dos}^{50}$, sendo que a concentração ideal encontrada foi de $10 \%{ }^{39,50,69,78}$ e a sua associação ao flúor ${ }^{45}$ proporcionou melhores resultados na prevenção da cárie ${ }^{31,32,39,69}$, propriedade que só é possível por existir disponibilidade e estabilidade do flúor presente no dentifrício, que continua mesmo após o envelhecimento ${ }^{31}$.
O xilitol não apresenta uma toxicidade que represente risco à saúde humana, sendo os efeitos colaterais encontrados: a diarréia osmótica e o desconforto abdominal ${ }^{7,12}$, ocasionados pela ingestão de grande quantidade deste produto (a dose máxima diária é de $20 \mathrm{~g}^{12}$ ). Outra desvantagem apresentada foi o custo elevado, que dificulta sua utilização em saúde pública ${ }^{7}$.

Pelas características até então descritas, há uma grande possibilidade do complexo flúor-xilitol ser um método preventivo bastante eficiente na clínica ortodôntica, possibilitando a minimização dos efeitos indesejáveis da utilização do aparelho ortodôntico fixo corretivo.

\section{PROPOSIÇÃO}

O objetivo deste estudo foi comparar a adesão de placa dentária à estrutura do dente, a diminuição da porcentagem de sangramento gengival e observar a influência da instrução de higiene bucal e da motivação, associadas à utilização dos dentifrícios contendo flúor e flúor-xilitol.

\section{MATERIAL E MÉTODOS Material}

Material utilizado para a avaliação dos índices de placa dentária e sangramento gengival

Os jovens foram avaliados em cadeira odontológica, com o auxílio de luz artificial do refletor. Para a quantificação dos índices utilizouse espelho clínico número 5 e sonda tipo IPC. Os resultados foram anotados em uma ficha de acompanhamento dos índices de placa dentária e sangramento gengival.

\section{Material para instrução de higienização}

A demonstração da instrução de higiene bucal deu-se com o auxílio de um manequim articulado com braquetes ortodônticos colados em todos os dentes e de uma escova de dente.

\section{Dentifrícios avaliados}

Três diferentes dentifrícios foram utiliza- 
dos: o dentifrício padrão (gel dental base com $\mathrm{pH}$ 6,6), o dentifrício flúor (gel dental base com $\mathrm{pH}$ 6,6 , acrescido de fluoreto de sódio a $1.100 \mathrm{ppm}$ ) e o dentifrício flúor/xilitol (gel dental base de $90 \mathrm{~g}$ com $\mathrm{pH} 6,6$, acrescido de fluoreto de sódio a $1.100 \mathrm{ppm}$ e xilitol a $10 \%$ ), sendo o gel dental base composto por $2 \%$ de carbomeximetilcelulose sódica; $20 \%$ de glicerina; $0,15 \%$ de metilparabeno; $0,05 \%$ de propilparabeno; $0,1 \%$ de lauril sulfato de sódio; $1 \%$ de flavorizante e água destilada qsp.

\section{Métodos}

Protocolo de estudo

O presente trabalho caracterizou-se por ser um estudo longitudinal, do tipo duplo cego cruzado, sendo que a amostra foi do tipo intencional e cruzada, ou seja, os índices de cada voluntário em uma fase foram comparados com os índices do mesmo voluntário em outra fase. A amostra compreendeu todos os jovens que se encontravam na faixa etária entre 14 e 17 anos, que juntamente com seus pais ou responsáveis concordaram em participar da pesquisa, totalizando 22, sendo 9 do gênero masculino e 13 do gênero feminino, que utilizavam aparelho ortodôntico fixo corretivo, atendidos na Clínica do Curso de Especialização em Ortodontia da Faculdade de Odontologia de Bauru da Universidade de São Paulo (FOB-USP).

Antes de iniciar propriamente a pesquisa os pais ou responsáveis receberam explicações individuais sobre os procedimentos que seriam realizados, a forma como deveriam proceder durante o período de coleta de dados, bem como receberam explicação sobre os motivos que justificavam a realização da pesquisa.

Em uma primeira sessão, foi realizada uma quantificação dos índices de placa dentária e de sangramento gengival, para permitir uma comparação entre a situação de saúde bucal em que se encontravam e os efeitos dos dentifrícios testados. Em seguida os voluntários receberam instruções individuais de escovação, onde se deu ênfase às regiões de maior acúmulo de placa dentária e de sangramento gengival.

Ao término da coleta do índice de sangramento gengival de cada fase, foi calculada a porcentagem de dentes que apresentavam sangramento à sondagem.

Foram avaliados todos os dentes de primeiro molar permanente de um lado ao outro, tanto no arco superior quanto no arco inferior, sendo que todos os dentes apresentavam colagem direta dos acessórios, exceto os primeiros molares permanentes que se apresentavam bandados.

Todos os dados foram coletados por um único examinador, para evitar qualquer tipo de desvio na pesquisa. $\mathrm{O}$ erro intra-examinador não foi realizado pois a quantidade de placa dentária não é constante, impossibilitando sua utilização.

Os jovens foram divididos em dois grupos (A e B), para evitar que a possibilidade de maior empenho em uma ou outra fase da pesquisa alterasse os resultados reais. A partir de então foram distribuídos os primeiros dentifrícios do estudo, sendo um dentifrício contendo flúor - gel dental base com pH 6,6 e 1.100ppm de fluoreto de sódio - e o outro um dentifrício contendo o complexo flúor-xilitol gel dental base com $\mathrm{pH}$ 6,6, 1.100ppm de fluoreto de sódio e xilitol a 10\% - dependendo do grupo ao qual pertenciam. Todos os jovens receberam ainda um gel dental base com pH 6,6 que foi utilizado uma semana antes de cada dentifrício do estudo, a fim de impedir o possível efeito residual dos dentifrícios que vinham utilizando anteriormente. Para evitar a indução do pesquisador a favorecer um ou outro dentifrício, eles apresentavam colorações diferentes (verde ou rosa) que só foram reveladas após o término da coleta dos dados, sendo o dentifrício verde o que continha apenas o flúor e o rosa o que continha o composto flúor-xilitol.

Os jovens do grupo A receberam, na primeira fase da pesquisa, o dentifrício manipulado de cor verde, enquanto os do grupo B receberam um dentifrício manipulado de cor rosa. Foram instruídos a utilizarem o dentifrício padrão por uma semana, a fim de evitar qualquer ação residual 
do dentifrício anteriormente utilizado. A partir da segunda semana passaram a utilizar um dos dentifrícios a serem testados, conforme o grupo ao qual pertenciam, durante 28 dias. Após este período os jovens voltaram para a primeira coleta de controle, onde foram anotados novamente os valores dos índices de placa e de sangramento gengival encontrados. $\mathrm{Na}$ ocasião receberam o novo dentifrício, sendo o rosa para o grupo A e o verde para o grupo B, sendo novamente instruídos a utilizarem o dentifrício padrão por uma semana e, em seguida, o novo dentifrício, por mais 28 dias. Também receberam um reforço sobre a técnica de escovação, já que os estudos revelam ser este o método mais eficaz de controle da placa dentária.

Passado este período, os jovens compareceram novamente para a avaliação, onde foram coletados os dados da segunda fase da pesquisa.

Durante o decorrer da pesquisa, os jovens e responsáveis foram orientados de maneira verbal e escrita a usar exclusivamente o dentifrício que estava sendo testado e a não realizar bochecho com nenhum tipo de produto químico.

O projeto foi aprovado pelo Comitê de Ética em Pesquisa da Faculdade de Odontologia de Bauru, atendendo as normas da Resolução 196/96 do conselho Nacional de Saúde, sendo que os responsáveis pelos voluntários receberam uma carta de informação e assinaram um termo de consentimento livre e esclarecido, concordando em participar do experimento.

\section{Métodos analíticos}

Para a realização da análise estatística dos dados obtidos, foi avaliada a porcentagem de dentes que apresentaram sangramento gengival em cada fase e os valores de placa dentária, pelos escores médios para cada indivíduo.

Após a obtenção dos dados de cada voluntário, os dados foram comparados para cada fase.

A avaliação da quantidade de placa dentária foi feita pela aplicação do índice proposto por Cian- cio $^{26}$ (Bonded Bracket Index - BBI) modificado. A modificação do índice original se deu na forma de visualização da placa dentária, onde não foi feita a evidenciação da mesma com fucsina, secando o dente e, em casos de dúvidas, com o auxílio da sonda IPC. A não evidenciação da placa dentária foi possível porque, inicialmente, foi realizado um estudo piloto e comparada a visualização da placa dentária com e sem a coloração da mesma. Como não houve diferença e devido ao fato da fucsina tingir os elásticos colocados no aparelho ortodôntico desagradando os voluntários, optou-se por esta modificação. $\mathrm{O}$ índice de Ciâncio ${ }^{26}$ é um índice próprio para Ortodontia e avalia apenas a face vestibular dos dentes, por ser esta a face de maior acúmulo de placa dentária, após a instalação do aparelho ortodôntico fixo corretivo, seguindo os critérios abaixo:

0 - ausência de placa;

1- presença de placa somente no braquete;

2- presença de placa no braquete e na superfície dentária, sem extensão gengival;

3- presença de placa no braquete e na superfície dentária, com extensão para a papila;

4- presença de placa no braquete e na superfície dentária, cobrindo parcialmente a gengiva;

5- presença de placa no braquete e na superfície dentária, cobrindo totalmente a gengiva.

$\mathrm{O}$ índice de sangramento gengival utilizado foi baseado no preconizado pela OMS, denominado Índice Periodontal Comunitário (IPC) ${ }^{66}$. Para realizar o exame utiliza-se uma sonda específica, que apresenta uma esfera de $0,5 \mathrm{~mm}$ na ponta e marcações que permitem identificar distâncias de até $11,5 \mathrm{~mm}$ da ponta da sonda. Esta sonda é denominada sonda IPC. No índice original, a boca é dividida em sextantes definidos pelos dentes: 18-14, 13-23, 24-28, 38-34, 33-43 e 44-48. A presença de dois ou mais dentes sem indicação de exodontia já viabiliza o exame do sextante, caso contrário o sextante é cancelado. Existem alguns dentes que são considerados 
dentes-índice e estes dentes variam conforme a idade. $\mathrm{Na}$ idade avaliada no presente estudo os dentes-índice são: 16, 11, 26, 36, 31 e 46, sendo que na ausência dos dentes-índice de um sextante, todos os outros dentes do sextante deveriam ser examinados, porém no presente estudo todos os dentes presentes na cavidade bucal, de primeiro molar a primeiro molar, foram examinados, ocasionando uma modificação na técnica originalmente preconizada. Essa modificação foi realizada para diminuir a possibilidade de erro. O exame deve ser realizado introduzindo a sonda IPC no sulco gengival, ligeiramente inclinada em relação ao longo eixo do dente, seguindo a configuração anatômica da superfície radicular. A sondagem deve ser realizada inicialmente na face vestibular e em seguida na face lingual ou palatina de todos os dentes a serem examinados. A força de sondagem não pode ser inferior a 20 gramas.

Para avaliação da situação encontrada, deve ser seguido o seguinte critério:

0 - sem sangramento gengival;

1- com sangramento gengival.

\section{Análise estatística}

Para a avaliação dos resultados, foram considerados apenas 22 jovens, para evitar diferença entre os grupos, portanto um dos voluntários foi excluído de maneira aleatória. Dos resultados obtidos,

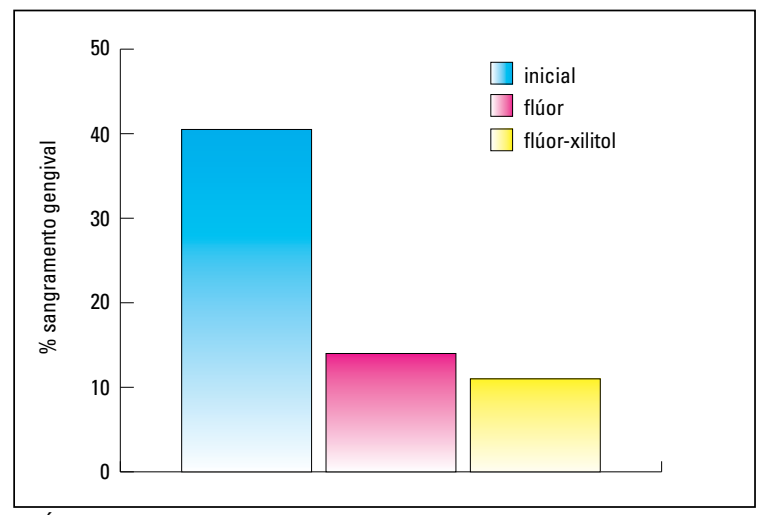

GRÁFICO 1 - Porcentagens médias de sangramento gengival na fase inicial e após a utilização de dentifrício contendo flúor e o complexo flúor-xilitol. foram comparados, através do teste $t$, os dois tipos de dentifrícios utilizados, em relação à porcentagem de sangramento gengival e aos escores do índice de placa dentária, dos grupos A e B.

A comparação entre as fases de utilização em cada grupo foi realizada pelo teste $t$ pareado.

\section{RESULTADOS}

Os gráficos 1 e 2 representam os resultados obtidos, a tabulação geral dos dados em relação ao índice geral de porcentagem de sangramento gengival e aos escores médios de placa dentária, respectivamente, conforme o dentifrício utilizado.

Como os dentifrícios foram utilizados em diferentes tempos, conforme o grupo a que pertenciam, não foi possível estabelecer um valor médio do resultado de cada dentifrício, sendo necessária uma comparação entre as fases de utilização, conforme pode ser observado nas tabelas 1, 2, 3 e 4 .

Pelas diferenças de resultados apresentadas em cada grupo nas fases inicial, primeira avaliação (T1) e segunda avaliação (T2), optou-se por comparar os grupos A e B em relação às fases de utilização e não mais ao componente químico presente nos dentifrícios, conforme mostram os gráficos 3 e 4 e a tabela 5 .

Baseada na tabela 5 e na análise estatística teste $\mathrm{t}$ com nível de significância de $5 \%$, a tabela 6 faz uma comparação entre os grupos

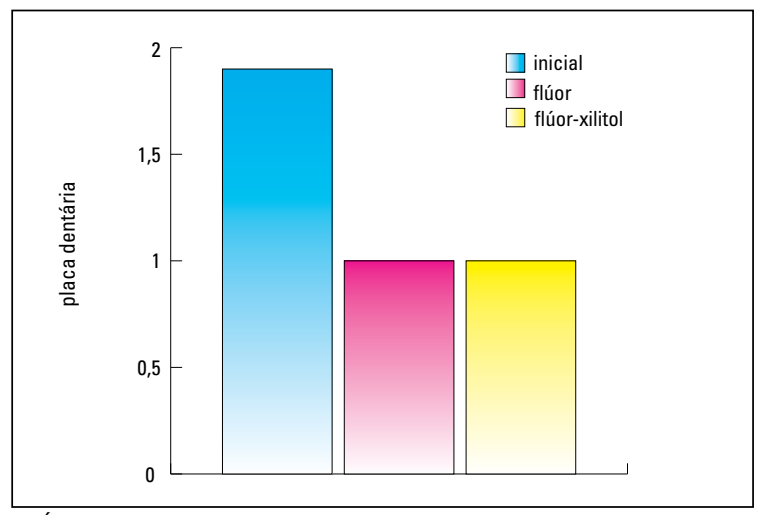

GRÁFICO 2 - Escores médios do índice de placa dentária na fase inicial e após a utilização de dentifrício contendo flúor e o complexo flúor-xilitol. 
Tabela 1 - Porcentagem de sangramento gengival inicial, após a utilização de dentifrício contendo flúor e após a utilização de dentifrício contendo flúor-xilitol, nos jovens do grupo A, na seqüência em que foram avaliados.

\begin{tabular}{cccc}
\hline jovem & $\% \mathbf{S i}$ & \%SF ( T1) & \%SX (T2) \\
\hline 1 & 16,7 & 0 & 0 \\
2 & 20,8 & 37,5 & 8,3 \\
3 & 37,5 & 4,2 & 8,3 \\
4 & 62,5 & 29,2 & 8,3 \\
5 & 65 & 20 & 0 \\
6 & 37,5 & 29,2 & 8,3 \\
7 & 40,9 & 13,6 & 4,5 \\
8 & 60 & 20 & 5 \\
9 & 60,9 & 17,4 & 0 \\
10 & 40,9 & 31,8 & 4,5 \\
11 & 35 & 15,0 & 0 \\
Média & $\mathbf{4 3 , 4 3}$ & $\mathbf{1 9 , 8 1}$ & $\mathbf{4 , 2 9}$ \\
\hline
\end{tabular}

* $\% \mathrm{Si}=$ porcentagem de sangramento na fase inicial; $\% \mathrm{SF}=$ porcentagem de sangramento com a utilização do dentifrício flúor e \%SX = porcentagem de sangramento com a utilização do dentifrício flúor-xilitol.

Tabela 3 - Porcentagem de sangramento gengival inicial, após a utilização de dentifrício contendo flúor-xilitol e após a utilização de dentifrício contendo flúor, nos jovens do grupo $B$, na seqüência em que foram avaliados.

\begin{tabular}{cccc}
\hline jovem & \%Si & \%SX (T1) & \%SF (T2) \\
\hline 12 & 50 & 5 & 0 \\
13 & 26,3 & 21,1 & 10,5 \\
14 & 20,8 & 8,3 & 0 \\
15 & 31,6 & 36,8 & 0 \\
16 & 45 & 20 & 5 \\
17 & 29,2 & 20,8 & 0 \\
18 & 58,3 & 16,7 & 25 \\
19 & 50 & 20,8 & 8,3 \\
20 & 35 & 5 & 5 \\
21 & 35 & 10 & 10 \\
22 & 27,3 & 27,3 & 22,7 \\
Média & $\mathbf{3 7 , 1 4}$ & $\mathbf{1 7 , 4 4}$ & $\mathbf{7 , 8 6}$ \\
\hline
\end{tabular}

* \% $\mathrm{Si}=$ porcentagem de sangramento na fase inicial; \%SF = porcentagem de sangramento com a utilização do dentifrício flúor e \%SX = porcentagem de sangramento com a utilização do dentifrício flúor-xilitol.

A e B quanto aos índices de porcentagem de sangramento gengival e escores de placa dentária, levando-se em consideração a fase de utilização de cada dentifrício.

Pela análise do teste $t$, não houve diferença es-
Tabela 2 - Escores médios de placa dentária nas fases inicial, após a utilização de dentifrício contendo flúor e após a utilização de dentifrício contendo flúor-xilitol, nos jovens do grupo A, na seqüência em que foram avaliados.

\begin{tabular}{cccc}
\hline jovem & $\mathbf{P i}$ & $\mathbf{P F}(\mathbf{T} 1)$ & $\mathbf{P X}$ (T2) \\
\hline 1 & 1,13 & 0,25 & 0,33 \\
2 & 2,13 & 1,58 & 0,63 \\
3 & 2,21 & 1,04 & 1,13 \\
4 & 1,83 & 1,67 & 1,46 \\
5 & 2,45 & 1,45 & 1,35 \\
6 & 1,33 & 1,29 & 0,33 \\
7 & 2,32 & 1,04 & 0,73 \\
8 & 2 & 1,35 & 0,95 \\
9 & 2,39 & 1,13 & 1 \\
10 & 2,09 & 1,41 & 0,55 \\
11 & 1,15 & 0,65 & 0,80 \\
Média & $\mathbf{1 , 9 1}$ & $\mathbf{1 , 1 7}$ & $\mathbf{0 , 8 4}$ \\
\hline
\end{tabular}

* $\mathrm{Pi}=$ escore médio de placa dentária na fase inicial; $\mathrm{PF}=$ escore médio de placa dentária com a utilização do dentifrício flúor e PX = escore médio de placa dentária com a utilização do dentifrício flúor-xilitol.

Tabela 4 - Escores médios de placa dentária inicial, após a utilização de dentifrício contendo flúor e após a utilização de dentifrício contendo flúor-xilitol, nos jovens do grupo $B$, na seqüência em que foram avaliados.

\begin{tabular}{cccc}
\hline jovem & $\mathbf{P i}$ & $\mathbf{P X}$ (T1) & $\mathbf{P F}$ (T2) \\
\hline 12 & 1,05 & 0 & 0 \\
13 & 2,11 & 0,74 & 1,05 \\
14 & 1,58 & 1,25 & 1,17 \\
15 & 2,37 & 1,63 & 0,63 \\
16 & 2,25 & 1,35 & 0,65 \\
17 & 1,79 & 0,79 & 0,63 \\
18 & 2,83 & 1,71 & 1,71 \\
19 & 1,88 & 1,71 & 0,96 \\
20 & 2,10 & 1,05 & 1,25 \\
21 & 1,85 & 0,95 & 0,15 \\
22 & 2,05 & 1,36 & 0,77 \\
Média & $\mathbf{1 , 9 9}$ & $\mathbf{1 , 1 4}$ & $\mathbf{0 , 8 2}$ \\
\hline
\end{tabular}

* $\mathrm{Pi}=$ escore médio de placa dentária na fase inicial; $\mathrm{PF}=$ escore médio de placa dentária com a utilização do dentifrício flúor e $\mathrm{PX}=$ escore médio de placa dentária com a utilização do dentifrício flúor-xilitol.

tatisticamente significante em relação ao uso dos dois dentifrícios testados, comparando os resultados entre as fases.

Foi realizada uma comparação intra-grupo para avaliar se houve alguma diferença estatisti- 
Tabela 5 - Diferença da porcentagem de sangramento gengival e dos escores de placa dentária encontrada entre os grupo A e B, quando comparados em relação aos tempos inicial, T1 e T2.

\begin{tabular}{cccc}
\hline variável & grupo A & grupo B & dif. A - B \\
\hline \% sang. inic. & 43,43 & 37,14 & 6,29 \\
\% sang. T1 & 19,81 & 17,44 & 2,37 \\
\% sang. T2 & 4,29 & 7,86 & $-3,57$ \\
\% sang. & $-23,62$ & $-19,70$ & 3,92 \\
T1 - inic. & & & \\
\% sang. & $-39,14$ & $-29,28$ & 9,86 \\
T2 - inic. & $-15,52$ & $-9,57$ & 5,95 \\
\% sang. T2- T1 & 1,91 & 1,99 & $-0,08$ \\
placa inic. & 1,17 & 1,14 & 0,03 \\
placa T1 & 0,84 & 0,82 & 0,02 \\
placa T2 & $-0,74$ & $-0,85$ & $-0,11$ \\
placa T1 - inic. & $-1,07$ & $-1,17$ & $-0,10$ \\
placa T2 - inic. & $-0,33$ & $-0,32$ & 0,01 \\
placa T2 - T1 & & & \\
\hline
\end{tabular}

Tabela 6 - Comparação entre os grupos A e B quanto à porcentagem de sangramento gengival e dos escores de placa dentária comparando a utilização dos dentifrícios contendo flúor e flúor-xilitol, quando estes foram utilizados na primeira ou segunda fase da pesquisa, segundo o teste $t$, com nível de significância de $5 \%$.

\begin{tabular}{cccccc}
\hline variável & grupo A & grupo B & dif. A - B & d.p. & valor t \\
\hline $\begin{array}{c}\text { \% sang } \\
\text { T1 - inic. }\end{array}$ & $-23,62$ & $-19,7$ & $-3,92$ & 16,64 & $-0,52$ \\
$\begin{array}{c}\text { \% sang } \\
\text { T2 - inic. }\end{array}$ & $-39,14$ & $-29,28$ & $-9,86$ & 12,65 & $-1,51$ \\
$\begin{array}{c}\% \text { sang. } \\
\text { T2 - T1 }\end{array}$ & $-15,52$ & $-9,57$ & $-5,95$ & 12,07 & $-1,24$ \\
$\begin{array}{c}\text { placa } \\
\text { T1 - inic. }\end{array}$ & $-0,74$ & $-0,85$ & 0,11 & 0,63 & 0,35 \\
$\begin{array}{c}\text { placa } \\
\text { T2 - inic. }\end{array}$ & $-1,07$ & $-1,17$ & 0,10 & 0,58 & 0,40 \\
$\begin{array}{c}\text { placa } \\
\text { T2 - T1 }\end{array}$ & $-0,33$ & $-0,32$ & $-0,01$ & $-0,15$ & 0,45 \\
\hline ** estatisticamente significante. & & &
\end{tabular}

camente significante entre as fases de utilização dos produtos, já que houve instrução de higiene bucal antes de iniciar a fase $\mathrm{Tl}$ e houve reforço de instrução antes de iniciar a fase T2 da pesquisa. Os resultados estão representados nas tabelas 7, 8, 9, 10, 11 e 12 .

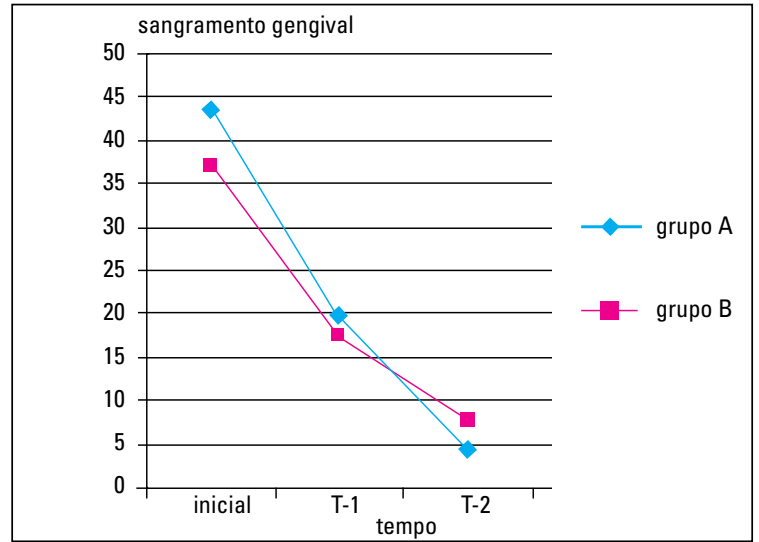

GRÁFICO 3 - Comparação entre as porcentagens médias de sangramento gengival das fases inicial, T1 e T2, dos grupos A e B.

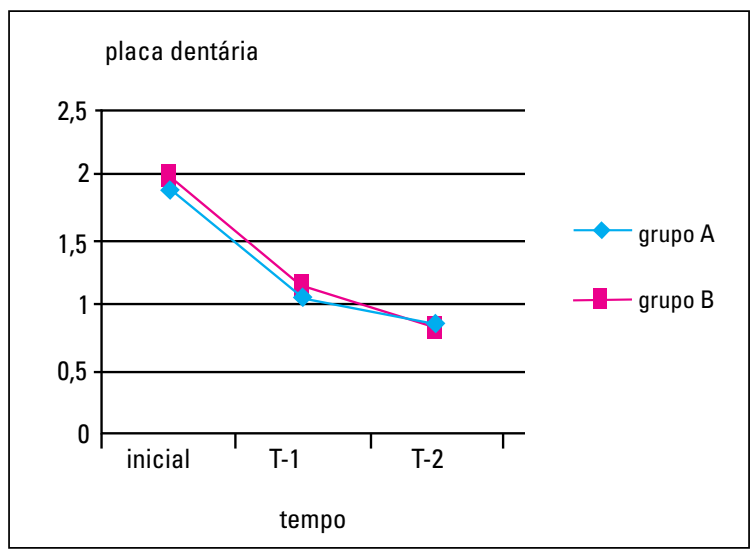

GRÁFICO 4 - Comparação entre os escores médios de placa dentária nas fases inicial, T1 e T2, dos grupos A e B.

\section{DISCUSSÃO}

Mesmo apresentando inúmeras vantagens em relação ao controle da placa dentária, este é o primeiro estudo realizado com o xilitol em pacientes ortodônticos.

Um dos primeiros pontos a ser levantado foi a forma de utilização do xilitol em pacientes ortodônticos.

O uso do xilitol em gomas de mascar mostrou resultados bastante satisfatórios ${ }^{3,16,58,64,69,74}$, porém sua utilização em gomas de mascar ou em pastilhas, poderia proporcionar descolagem dos acessórios, bem como a remoção das bandas ortodônticas, inviabilizando o seu uso. 
Tabela 7 - Porcentagem de sangramento gengival nas fases inicial e T1, nos grupos A e B, e comparação intra-grupos da fase inicial para a fase $\mathrm{T} 1$.

\begin{tabular}{cccccc}
\hline grupo & \% sang. inic. & \% sang. T1 & $\begin{array}{c}\text { \% sang. } \\
\text { inic. - T1 (IPM) }\end{array}$ & d.p. & valor t \\
\hline grupo A & 43,43 & 19,81 & $23,62(54,40 \%)$ & 18,58 & 0,21 \\
grupo B & 37,14 & 17,44 & $19,70(53,04 \%)$ & 16,64 & 3,93 \\
\hline
\end{tabular}

** estatisticamente significante

IPM = índice percentual de melhora.

Tabela 8 - Porcentagem de sangramento gengival nas fases $T 1$ e T2, nos grupos A e B, e comparação intra-grupos entre as fases $\mathrm{T} 1 \mathrm{e}$ T2.

\begin{tabular}{ccccccc}
\hline grupo & \% sang. T1 & \% sang. T2 & $\begin{array}{c}\text { \% sang. } \\
\text { T1 - T2 (IPM) }\end{array}$ & d.p. & valor t & p \\
\hline grupo A & 19,81 & 4,29 & $15,52(78,53 \%)$ & 10,37 & 4,96 & $0,00057^{* *}$ \\
grupo B & 17,44 & 7,86 & $9,57(54,93 \%)$ & 12,07 & 2,63 & $0,02513^{* *}$ \\
\hline
\end{tabular}

** estatisticamente significante.

Tabela 9 - Diferença entre a redução da porcentagem de sangramento gengival dos grupos A e B, entre as fases inicial e T2.

\begin{tabular}{cccc}
\hline grupo & $\%$ sang. inic & $\%$ sang. T2 & $\%$ sang. inic. - T2 (ITM) \\
\hline grupo A & 43,43 & 4,29 & $39,14(90,13 \%)$ \\
grupo B & 37,14 & 7,86 & $29,28(78,84 \%)$ \\
\hline
\end{tabular}

** estatisticamente significante

ITM = índice total de melhora.

Tabela 10 - Diferença dos escores de placa dentária entre as fases inicial e T1, nos grupos A e B, e comparação intra-grupos da fase inicial para a fase T1.

\begin{tabular}{cccccc}
\hline grupo & placa inic. & placa T1 & $\begin{array}{c}\text { placa inic. - T1 } \\
\text { (IPM) }\end{array}$ & d.p. & valor t \\
\hline grupo A & 1,91 & 1,17 & $0,74(38,75 \%)$ & 0,42 & 5,86 \\
grupo B & 1,99 & 1,14 & $0,85(42,71 \%)$ & 0,35 & $8,00002 * *$ \\
\hline
\end{tabular}

** estatisticamente significante

Tabela 11 - Diferença dos escores de placa dentária entre as fases T1 e T2, nos grupos A e B, e comparação intra-grupos das fases T1 e T2.

\begin{tabular}{ccccccc}
\hline grupo & placa T1 & placa T2 & placa T1 - T2 (IPM) & d.p. & valor t \\
\hline grupo A & 1,17 & 0,84 & $0,33(28,21 \%)$ & 0,42 & 2,59 \\
grupo B & 1,14 & 0,82 & $0,32(28,07 \%)$ & 0,45 & 2,38 & $0,38790 * * 21 *$ \\
\hline
\end{tabular}

** estatisticamente significante.

Tabela 12 - Diferença entre a redução dos escores médios de placa dentária nos grupos A e B, entre as fases inicial e T2.

\begin{tabular}{ccccc}
\hline grupo & placa inic. & placa T2 & placa inic. - T2 (ITM) \\
\hline Grupo A & 1,91 & 0,84 & $1,07(56,02 \%)$ \\
Grupo B & 1,99 & 0,82 & $1,17(58,79 \%)$ \\
\hline
\end{tabular}


Em relação ao seu emprego em enxaguatórios bucais, este poderia ser um método de escolha para a presente pesquisa, conforme os resultados encontrados por Luís et al. ${ }^{56}$, mas os trabalhos realizados por Giertsen, Emberland e Scheie ${ }^{43}$ e Gonçalves et al. ${ }^{44}$ não demonstraram resultados estatisticamente significante melhores que os enxaguatórios que continham apenas flúor em sua composição.

A escolha da utilização do xilitol em dentifrícios se deu pelas propriedades deste produto, sendo uma substância que, ao ser associada com a limpeza mecânica dos dentes, tem a finalidade de limpar as áreas acessiveis da superfície dentária; polir os dentes, tornando-os mais lisos e com menor risco de retenção de placa dentária; remover manchas extrínsecas e melhorar a saúde da gengiva, além de tornar mais agradável a escovação. Os dentifrícios modernos são cientificamente formulados e apresentam propriedades terapêuticas no controle da cárie e na manutenção de toda a saúde bucal ${ }^{15}$.

A concentração de xilitol no dentifrício formulado para o presente estudo foi de $10 \%$, seguindo os resultados já encontrados em outros estu$\operatorname{dos}^{39,50,69}$.

$\mathrm{Na}$ presente pesquisa, a utilização do dentifrício contendo o complexo flúor-xilitol foi associada ao método mecânico de escovação dentária e motivação do paciente que, segundo a literatura nos mostra, é de fundamental importância para a saúde bucal de pacientes ortodônticos ${ }^{61,67}$. A utilização do dentifrício contendo o complexo flúor-xilitol foi comparada com a utilização de um dentifrício contendo flúor, ambos associados ao método de remoção mecânica da placa dentária pela escovação e motivação do paciente. Esta associação entre um método mecânico e um método químico de controle de placa dentária e de sangramento gengival mostrou resultados satisfatórios no trabalho de Carvalho e Lascala ${ }^{24}$. $\mathrm{Na}$ avaliação do gráfico 1 é possivel observar que houve uma elevada redução da porcentagem média de sangramen- to gengival, tanto com a utilização do dentifrício contendo flúor, como também com a utilização do dentifrício contendo o complexo flúor-xilitol. Pela análise estatística realizada pelo teste $t$, não houve diferença estatisticamente significante entre a utilização dos dois dentifrícios testados, porém houve diferença estatisticamente significante entre a fase inicial e os dois grupos avaliados. Já em relação ao escore médio de placa dentária, mostrado no gráfico 2, houve redução com a utilização dos dois dentifrícios analisados, porém ambos apresentaram o mesmo escore de placa dentária.

No estudo de Gaffar et al. ${ }^{39}$ foram comparados um dentifrício contendo $10 \%$ de xilitol e $1.100 \mathrm{ppm}$ de fluoreto de sódio a um dentifrício contendo $1.100 \mathrm{ppm}$ de fluoreto de sódio, um outro padrão que também foi adotado no presente estudo. $\mathrm{Na}$ ocasião, os autores realizaram o trabalho em animais e seres humanos e puderam observar que o dentifrício contendo flúor e xilitol se mostrou superior na proteção de cárie, quando comparado ao dentifrício contendo apenas o fluoreto de sódio. Já no presente trabalho, realizado com pacientes ortodônticos, não foram encontradas diferenças estatisticamente significantes na redução da placa dentária e do sangramento gengival entre os dentifrícios avaliados, porém os melhores resultados, principalmente em relação ao sangramento gengival, foram encontrados quando foi utilizado o dentifrício contendo fluoreto de sódio e xilitol, conforme pode ser observado na tabela 5 .

Nas tabelas 7, 8 e 9, que mostram os índices parcial e total de melhora da porcentagem de sangramento gengival, é possível visualizar que a melhora sempre foi superior na fase em que estava sendo utilizado o dentifrício contendo o complexo flúor-xilitol, tanto na comparação entre as fases, como na comparação inicial e final (T2), sendo que quando o mesmo era associado à motivação $\mathrm{e}$ à instrução periódica de higiene bucal, sua utilização proporcionou uma redução total de 90,13\% de sangramento gengival, contra $78,84 \%$ quando da utilização do dentifrício sem o xilitol (Tab. 9). 
A redução percentual do índice de sangramento gengival entre o grupo $\mathrm{A}$, que utilizou o dentifrício contendo flúor e xilitol na fase T2, e o grupo B, que utilizou o dentifrício contendo o flúor na fase T2, mostrou que a redução percentual de sangramento gengival do grupo A foi 23,60\% (78,53\% - 54,93\%) maior que a redução de sangramento gengival do grupo $\mathrm{B}$, conforme pode ser observado na tabela 9, quando foram comparadas as fases $\mathrm{Tl}$ e T2 em cada grupo.

A importância da motivação do paciente, que foi apresentada por Almeida, Abrão ${ }^{6}$; Icaza Saldaña et al. ${ }^{48}$ e Pinzan et al. ${ }^{67,68}$, como de fundamental importância no controle da placa dentária, foi comprovada no presente trabalho, observandose que os melhores resultados para os índices de placa e sangramento gengival foram encontrados na fase T2 da pesquisa, conforme tabela 5, independente do produto utilizado em cada fase, sendo que, tanto para o grupo A como para o grupo B, a diminuição dos índices de placa e de sangramento gengival das fases inicial para $\mathrm{Tl}$ e de T1 para T2, apresentou uma redução estatisticamente significante, como pode ser observado nas tabelas 7, 8, 10 e 11. Os valores percentuais de redução de placa dentária, observados na tabela 10 , mostram que o grupo $\mathrm{B}$, que utilizou na fase T1 o dentifrício contendo flúor e xilitol, reduziu $3,96 \%(42,71 \%-38,75 \%)$ mais placa dentária que o grupo $\mathrm{A}$, que na fase $\mathrm{Tl}$ utilizou o dentifrício contendo apenas o flúor, mostrando um resultado mais favorável para o dentifrício contendo flúor associado ao xilitol.

Os valores percentuais da redução de placa dentária entre os dois grupos foram praticamente os mesmos, sendo que no grupo A esta redução foi maior que no grupo B em apenas $0,14 \%(28,21 \%$ - 28,07\%), não demonstrando diferença entre os grupos, conforme pode ser observado na tabela 11 .

Para avaliar a redução total dos escores de placa dentária entre os grupos A e B, comparou-se, na tabela 12 , as fases inicial e T2.

A redução percentual de placa dentária entre os dois grupos apresentou pouca diferença, sendo que houve uma melhora maior no grupo $B$, que utilizou na fase $\mathrm{T} 2$ o dentifrício contendo apenas o flúor em sua composição, e esta redução foi 2,77\% superior ao resultado médio do grupo A.

Na comparação entre as fases de utilização foi possível observar que, para cada uma, os valores de placa dentária e sangramento gengival diminuíram, conforme as tabelas 1, 2, 3 e 4, mostrando que a associação de um método químico e um método mecânico de controle da placa dentária, quando combinados com o processo de motivação do paciente, foi capaz de minimizar os efeitos indesejáveis proporcionados pela instalação do aparelho ortodôntico fixo corretivo.

O presente estudo seguiu o protocolo de instrução de higiene bucal, acompanhamento e motivação realizado por Matos, Vianna e Pitta ${ }^{61}$, onde os autores realizaram um programa de higiene bucal mecânica, com sessão individual de orientação e reforço mensal, sem nenhuma tentativa de introduzir técnicas de escovação padronizadas.

A análise dos escores médios de placa dentária seguiu o padrão dos trabalhos realizados por Icaza Saldaña et al. ${ }^{48}$ e por Pinzan et al. ${ }^{67}$, onde também foi utilizado o índice de Ciancio $^{26}$ (BBI), por se tratar de um índice próprio para a avaliação de pacientes ortodônticos, porém não foi realizada a evidenciação da placa dentária.

A pesquisa mostrou que foram encontrados os melhores resultados de redução de placa dentária e de sangramento gengival nos 28 primeiros dias da pesquisa ( $\mathrm{Tl}$ ), independente do dentifrício utilizado, indo ao encontro das pesquisas que mostram que os melhores resultados ocorrem quando os índices de placa e de sangramento gengival encontram-se mais elevados. Tais resultados podem ser encontrados comparando as médias de redução da placa dentária e da porcentagem de sangramento gengival e do índice parcial de melhora nas tabelas 7, 8, 10 e 11. A maior diminuição dos problemas de saúde bucal quando os índices se encontram mais altos é natural e comprovada por Bastos, 
Lopes e Ramires ${ }^{15}$, que observaram que quando os índices se encontravam menores, eles continuavam diminuindo, embora esta redução fosse em menor porcentagem, fato observado no presente trabalho, onde os resultados mostraram que, nos 28 dias subseqüentes da pesquisa, os valores da porcentagem de sangramento gengival e do índice de placa dentária continuaram tendo uma redução significativa, porém em menor quantidade, mostrando que a associação do elemento químico, instrução de higiene bucal e motivação continuaram proporcionando uma diminuição dos índices de placa dentária e de sangramento gengival.

Esta pesquisa se mostrou de grande importância para o clínico geral, pois, embora não tenha comprovado estatisticamente que a associação de um dentifrício contendo flúor e xilitol a métodos de instrução e motivação tenha se mostrado mais eficaz que quando estes métodos foram associados ao uso de dentifrícios contendo apenas o flúor em sua composição, uma avaliação sobre o percentual total de melhora demonstrou que os melhores resultados no controle do sangramento gengival foram encontrados quando utilizou-se o dentifrício contendo o xilitol, conforme a tabela 9 , porém esta melhora não foi observada em relação aos escores médios de placa dentária, conforme pode ser comprovado na tabela 12 .

Provavelmente, alguns fatores podem ter influenciado na retenção da placa dentária, entre eles a presença de elásticos e amarrilhos conjugados em alguma das fases avaliadas, que certamente dificultam a higienização e proporcionam maior acúmulo de placa, além do fato de nem sempre ter sido realizada a escovação prévia à análise. Outro fator que permite o maior acúmulo de placa na estrutura dentária e dificulta a sua remoção mecânica é o excesso de resina encontrado ao redor dos braquetes, fato que já havia sido descrito por Pinzan et al. ${ }^{67}$

Talvez, por este motivo os resultados referentes ao percentual de sangramento gengival sejam mais precisos, já que o sangramento é resultado de uma inflamação gengival e, portanto, é menos alterado em uma análise momentânea.

Dentifrícios contendo xilitol estão sendo introduzidos agora no mercado, porém ainda é muito difícil encontrá-los. Por este motivo, os dentifrícios utilizados na pesquisa tiveram que ser manipulados, trazendo algumas desvantagens para a sua indicação, por se tornar mais difícil de ser adquirido, ter um custo mais elevado e não ter uma aceitabilidade muito grande por parte dos pacientes, devido ao fato de não apresentarem um sabor refrescante como o dos dentifrícios comercializados.

Outros trabalhos devem ser realizados, levando em consideração os fatores acima citados, em relação à fase de tratamento e dispositivos presentes no momento da avaliação; sugerindo uma higienização prévia à coleta dos dados; pesquisando a disponibilidade do dentifrício contendo xilitol no mercado e avaliando a aceitabilidade do dentifrício entre os participantes da pesquisa.

$\mathrm{Na}$ impossibilidade ou dificuldade de utilizar um dentifrício contendo flúor e xilitol associados, o ortodontista precisa estar atento à importância de instruir e motivar seus pacientes em relação à escovação dentária, além de realizar limpeza periódica nos dentes de seus pacientes, para que estes não atinjam um grau de inflamação gengival irreversível ou adquiram cáries no decorrer da correção ortodôntica.

\section{CONCLUSÕES}

Com base nos resultados obtidos parece lícito concluir que, em uma comparação entre os grupos A e B, o dentifrício contendo $10 \%$ de xilitol e $1.100 \mathrm{ppm}$ de fluoreto de sódio não apresentou diminuição estatisticamente significante na porcentagem de sangramento gengival em pacientes ortodônticos, quando comparado ao dentifrício que continha apenas $1.100 \mathrm{ppm}$ de flúor em sua composição; embora não tenha apresentado diferença estatisticamente significante, o dentifrício contendo $10 \%$ de xilitol e $1.100 \mathrm{ppm}$ de fluoreto de sódio teve um percentual de melhora superior 
ao observado com o uso do dentifrício contendo $1.100 \mathrm{ppm}$ de fluoreto de sódio, em relação ao sangramento gengival; o dentifrício contendo $10 \%$ de xilitol e 1.100ppm de fluoreto de sódio não apresentou diminuição estatisticamente significante na redução dos escores de placa dentária, quando comparado ao dentifrício convencional; e os dois dentifrícios avaliados não apresentaram diminuição estatisticamente significante, quando comparados entre si, mas a diminuição dos índices de placa e de sangramento gengival das fases Tl (após 28 dias) e T2 (nos 28 dias subseqüentes), comparada aos valores iniciais, foi significante para os dois dentifrícios testados.

Em uma comparação entre os dentifrícios dentro dos mesmos grupos foi possível observar que os dentifrícios contendo o complexo flúor-xilitol e o dentifrício convencional reduziram de manei- ra estatisticamente significante a porcentagem de sangramento gengival e os escores de placa dentária, tanto da fase inicial para o tempo $\mathrm{Tl}$, quanto do tempo T1 para o tempo T2, nos dois grupos avaliados; os menores índices de placa dentária e de sangramento gengival foram encontrados na fase T2, independente do dentifrício utilizado nesta fase, comprovando a importância de se instruir periodicamente o paciente ortodôntico sobre a escovação dentária bem como motivá-lo para manter sua saúde bucal.

Portanto, há uma tendência em se afirmar que a associação dos dentifrícios avaliados e a instrução de higienização e constante motivação são capazes de reduzir gradativamente os índices de sangramento gengival e de placa dentária.

Enviado em: junho de 2005 Revisado e aceito: agosto de 2005

\title{
Influence of fluorine-xylitol complex in the dental plaque and gingival bleeding control in herbiatric patients with fixed orthodontic brace
}

\begin{abstract}
Aim: to evaluate the effects of a dentifrice containing fluorine/xylitol in the reduction of the adhesion of the plaque to the dental structure, as well as in the gingival bleeding index in patients who had orthodontic braces. Methods: 22 teenagers, in between 14 and 17 years old were evaluated. After the initial quantification of the indexes, they received instructions of brushing and started to use only the dentifrices from the research. There was a random division of the sample into two groups, A and B. In the first week, they all used a standard dentifrice and since the second week the teenagers from group $A$ received a dentifrice with fluorine, while the ones from group $B$ received a dentifrice containing the fluorine-xylitol complex, using for 28 days, when they were evaluated again (T1). There was an inversion of dentifrices for second phase. Results: the results were compared intra-groups and in both groups there was a statistically significant reduction between phases initial and T1, initial and T2 and between T1 and T2. However, comparing the groups, there was no statistically significant difference between them, though the dentifrice containing fluorine/ xylitol provided a percentage of reduction of gingival bleeding index bigger than the one containing only sodium fluoride, specially between phases initial and T2, where reduction in group A was $90.13 \%$ and in group B was $78.84 \%$. Conclusion: the utilization of dentifrice containing fluorine and xylitol, associated to instruction and motivation, seems to be a promising resource for maintenance of oral health in orthodontic patients.
\end{abstract}

Key words: Fixed orthodontic appliance. Dentifrice. Xylitol. Herbiatric patients. Dental plaque. Gingival bleeding.

\section{REFERÊNCIAS}

1. AALTONEN, A. S. et al. Efficacy of a slow-release device containing fluoride, xylitol and sorbitol in preventing infant caries. Acta Odontol Scand, Oslo, v. 58, no. 6, p. 285-92, Dec. 2000.

2. ADAMS, R. J. The effects of fixed orthodontic appliances on the cariogenicity, quantity and microscopic morphology of oral lactobacilli. J Oral Med, St. Louis, v. 22, no. 3, p. 88-98, July 1967.
3. ALANEN, P.; ISOKANGAS, P.; GUTMANN, K. Xylitol candies in caries prevention: results of a field study in Estonian children. Community Dent Oral Epidemiol, Copenhagen, v. 28, no. 3, p. 218-224, June 2000.

4. ALANEN, P. HOSTI, M. L.; PIENIHÄKKINEN, K. Sealants and xylitol chewing gum are equal in caries prevention. Acta Odontol Scand, Oslo, v. 58, no. 6, p. 279-284, Dec. 2000. 
5. ALEXANDER, S. A.; RIPA, L. W. Effects of self-applied topical fluoride preparations in orthodontic patients. Angle Orthod, Appleton, v. 70, no. 6, p. 424-430, Dec. 2000.

6. ALMEIDA, F. M. S. de; ABRÃO, J. Orientação e controle da placa bacteriana em pacientes portadores do aparelho ortodôntico. Rev Odontoped Atual Clín, São Paulo, n. 4, p. 119-130, out./dez. 1997.

7. ANDRADE, J. P.; VOLSCHAN, B. C. G. A praticidade do uso de adoçantes alternativos. Rev Bras Odontol, Rio de Janeiro, v. 55, n.1, p. 40-44, jan./fev. 1998.

8. AUTIO, J. T.; COURTS, F. J. Acceptance of the xylitol chewing gum regimen by preschool children and teachers in Head Start program: a pilot study. Pediatr Dent, Chicago, v. 23, no.1, p. 71-74, Jan./Feb. 2001.

9. BABAY, N. A.; AL-JASSER, N. Subgingival irrigation effects of chlorexidine or sanguinarie on gingivitis in orthodontic patients. J Clin Pediatr Dent, Birmingham, v. 20, no. 3, p. 225-228, Spring 1996.

10. BACCHI, E. O. S.; PRATES, N. S.; ATTIZZANI, A. Profilaxia buçodental em Ortodontia. Rev Gaúcha Odontol, Porto Alegre, v. 45, n. 6, p. 342-346, nov./dez. 1997

11. BASTOS, J. R. de M. Prevenção primária-primária. Rev Gaúcha Odontol, Porto Alegre, v. 44, n. 3, p. 185, maio./jun. 1996.

12. BASTOS, J. R. de M.; HEINTZE, S. D.; PRADO, S. V. Contribuição ao estudo da toxicologia da xilitol e do flúor. UFES: Rev Odontol, Vitória, n. 2, p.78-84, jul./dez. 2000.

13. BASTOS, J. R. de M.; HENRIQUES, J. F. C.; OLYMPIO, K. P. K. Manual de prevenção de cárie dentária e doença periodontal em pacientes sob tratamento ortodôntico. Bauru: Faculdade de Odontologia de Bauru, 2002.

14. BASTOS, J. R. de M.; LOPES, E. S.; FREITAS, S. F. T. Panorama mundial após 50 anos de uso do flúor. Rev Gaúcha Odontol, Porto Alegre, v. 41, n. 5, p. 309-11, set./out. 1993.

15. BASTOS, J. R. de M.; LOPES, E. S.; RAMIRES, I. Manual de odontologia preventiva \& social. Bauru, 2001.

16. BIRKHED, D. Cariologic aspects of xylitol and its use in chewing gum: a review. Acta Odontol Scand, Oslo, v. 52, no. 2, p.116-127, \}Apr. 1994.

17. BISHARA, S. E. et al. Effect of a fluoride-releasing self-etch acidic primer on the shear bond strength of orthodontic brackets. Angle Orthod, Appleton, v. 72, no. 3, p.199-202, June 2002

18. BOYD, R. L. Comparison of three self-applied topical fluoride preparations for control of descalcification. Angle Orthod, Appleton, v. 63, no. 1, p. 25-30, Spring 1993.

19. BOYD, R. L.; CHUN, Y. S. Eighteen-month evaluation of the effects of a $0,4 \%$ stannous fluoride gel on gingivitis in orthodontic patients. Am J Orthod Dentofacial Orthop, St. Louis, v. 105, no. 1, p. 35-41, Jan. 1994

20. BOWMAN, S. J. A utilização do Duraflor na redução da descalcificação durante o tratamento ortodôntico. R Dental Press Ortodon Ortop Facial, Maringá, v. 6, n. 1, p. 79-81, jan./fev. 2001.

21. BRIGHTMAN, L. J. et al. The effects of a $0,12 \%$ chlorexidine gluconate mouthrinse on orhodontic patients aged 11 through 17 with estabilished gingivitis. Am J Orthod Dentofacial Orthop, St. Louis, v. 100, no. 4, p. 324-329, Oct. 1991.

22. BURKET, L. W. The effects of orthodontic treatment on the soft periodontal tissues. Am J Orthod, St. Louis, v. 49, no. 9, p. 660-671, Sept. 1963.

23. CARVALHO, L. E. P et al. Clorexidina em Odontologia: uso do gluconato de clorexidina no controle da placa bacteriana. Rev Gaúcha Odontol, Porto Alegre, v. 39, n. 6, p. 423-427, nov./dez. 1991.

24. CARVALHO, L. S.; LASCALA, N. T. Estudos em pacientes portadores de aparelho ortodôntico, correlacionando os índices de placa e gengival à escovação dental e com bochechos de fluoreto de sódio e com Cepacol. Ortodontia, São Paulo, v. 23, n. 3, p. 35-47, set./dez. 1990.

25. CAVEZZI JÚNIOR, O. et al. Efeitos dos bochechos de clorexidina na saúde gengival em pacientes portadores de aparelhos ortodônticos. Periodontia, Fortaleza, v. 5, n. 3, p. 309-311, jan./jun. 1996

26. CIANCIO, S. G. et al. A comparison of plaque accumulation in bonded vs. bonded teeth. J Dent Res, Washington, D. C., v. 64, p. 359, 1985.

27. COOK, P. A. Direct bonding with glass ionomer cement. J Clin Orthod, Boulder, v. 24, no. 8, p. 509-511, Aug. 1990.

28. COONAR, A. K.; JONES, S. P.; PEARSON, G. J. An ex vivo investigation into the fluoride release and absorption profiles of three orthodontic adhesives. Eur J Orthod, London, v. 23, no. 4, p. 417-424, Aug. 2001.

29. CUNHA, L. S. C. et al. Uso do xilitol como agente anticariogênico. 2003. Dissertação (Mestrado)-Faculdade de Odontologia de Bauru, Universidade de São Paulo, Bauru, 2003.

30. CUOGHI, O. O. A. et al. Avaliação e comparação da eficácia de três tipos diferentes de escovas dentais associadas a outros recursos de controle de placa bacteriana em pacientes submetidos ao tratamento ortodôntico corretivo. R Dental Press Ortodon Ortop Facial, Maringá, v. 6, n. 3, p. 47-53, maio/jun. 2001.

31. CURY, J. A. Avaliação de um gel dentifrício contendo xilitol e flúor. Rev Bras Odontol, Rio de Janeiro, v. 64, n. 4, p. 36-42, jul./ago. 1987.

32. DJAHJAH, C. A. et al. Efeito de um programa não invasivo na progressão da cárie dentária. Rev Bras Odontol, Rio de Janeiro, v. 52, n. 4, p. 36-41, jul./ago. 1995.

33. DONLY, K. J.; ISTRE, S.; ISTRE, T. In vitro enamel remineralization at orthodontic band margins cemented with glass ionomer cement. Am J Orthod Dentofacial Orthop, St. Louis, v. 107, no. 5, p. 461-464, May 1995.

34. ELIADES, T. et al. Comparison of enamel colour changes associated with orthodontic bonding using two different adhesives. Eur J Orthod, London, v. 23, no. 1, p. 85-90, Feb. 2001.

35. FAJEN, V. B. et al. An in vitro evolution of three glass ionomer cement. Am J Orthod Dentofacial Orthop, St. Louis, v. 97, no. 4, p. 316-322, Apr. 1990

36. FERES, M. A. L. Pacientes problemáticos. Rev Goiana Ortodon, Goiás, v. 1, n. 1, p. 28-29, 1995.

37. FERREIRA, V. M. G. et al. Avaliação do risco de cárie antes, no início e ao final do tratamento ortodôntico fixo, em pacientes submetidos a um programa de saúde bucal. Rev Aboprev, [S.I.], n. 1, p. 3-9, maio 1999

38. FRAZIER, M. C.; SOUTHARD, T. E.; DOSTER, P. M. Prevention of enamel desmineralization during orthodontic treatment: an in vitro study using pit and fissure sealants. Am J Orthod Dentofacial Orthop, St. Louis, v. 110, no. 5, p. 459-465, Nov. 1996.

39. GAFFAR, A. et al. Cariostatic effects of $x y l i t o l / N a F$ dentifrice in vivo. Int Dent J, London, v. 48, no. 1, p. 32-39, Feb. 1998.

40. GARIB, D. G. et al. Efeito do uso de gluconato de clorexidina e do cloreto de cetilpiridíneo em bochechos como meio complementar da higiene bucal em pacientes sob tratamento ortodôntico. Ortodontia, São Paulo, v. 30, n. 2, p. 22-30, mar./ago. 1997.

41. GERÔNIMO, D. H.; TOGASHI, A. Y.; HENRIQUES, J. F. C. Avaliação comparativa dos efeitos dos acessórios ortodônticos na saúde gengival e no índice de placa em pacientes com e sem orientação sobre métodos de higiene bucal. Ortodontia, São Paulo, v. 28, n. 3, p. 27-33, set./dez. 1994.

42. GHERSEL, H.; GHERSEL, T. Placa bacteriana e aparelho ortodôntico fixo: uma avaliação. Rev Inst Ciênc Saúde, São Paulo, v. 8, n. 2, p.15-17, jul./dez. 1990

43. GIERTSEN, E.; EMBERLAND, H.; SCHEIE, A. A. Effects of mouth rinses with xylitol and fluoride on the dental plaque and saliva. Caries Res, Basel, v. 33, no. 1, p. 23-31, Jan./Feb. 1999.

44. GONÇALVES, N. C. L. A. V. et al. Efeito das soluções fluoretadas contendo xilitol e sorbitol no número de estreptococos do grupo mutans na saliva de seres humanos. Rev Panam Salud Publica, Washington, D.C., v. 9, n. 1, p. 30-34, 2001.

45. GONÇALVES, B. C.; UZEDA, M.; FEITOSA, A. Avaliação de dentifrícios com xilitol e/ou flúor Rev Gaúcha Odontol, Porto Alegre, v. 41, n. 5, p. 267-270, set./out. 1993.

46. GRANJEIRO, J. M. et al. O cloreto de cetilpiridínio e a placa bacteriana: uma revisão. Rev Assoc Paul Cir Dent, São Paulo, v. 47, n. 2, p. 1019-1022, mar./abr. 1993.

47. HUJOEL, P. P. et al. The optimum time to initiate habitual xylitol 
gum-chewing for obtaining long-term caries prevention. J Dent Res, Washington, D. C., v. 78, no. 3, p. 797-803, Mar. 1999

48. ICAZA SALDAÑA, J. E. et al. Avaliação comparativa do controle da placa bacteriana e da gengivite em pacientes sob tratamento ortodôntico sem orientação e com métodos de higiene supervisionados e de controle profissional. Ortodontia, São Paulo, v. 22, n. 2, p. 29-39, jul./dez. 1988.

49. ISOKANGAS, P. et al. Occurrence of dental decay in children after maternal consumption of xylitol chewing gum, a follow-up from 0 to 5 years of age. J Dent Res, Washington, D. C., v. 79, no. 11, p. 1885-1889, Nov. 2000

50. JANNESSON, L.; RENVERT, S.; BIRKHED, D. Effect of xylitol in an enzyme containing dentifrice without sodium lauryl sulfate on mutans streptococci in vivo. Acta Odontol Scand, Oslo, v. 55, no. 2, p. 111-118, Feb. 1997

51. JORDAN, C. N. Prevention of white spot enamel formation during orthodontic treatment. Gen Dent, v. 46, no. 5, p. 498-502, Sept./Oct. 1998.

52. KOPARAL, E.; ERTUGRUL, F. SABAH, E. Effect of chewing gum on plaque acidogenicity. J Clin Pediatr Dent, Birmingham, v. 24, no. 2, p.129-132, Winter 2000

53. LASCALA, C. E.; BELLUZZO, R. H. L.; LASCALA JÚNIOR, N.T. Procedimentos de motivação e higiene bucal em pacientes sob tratamento ortodôntico objetivando a saúde periodontal. Periodontia, Fortaleza, v. 5, n. 4, p. 324-327, jul./dez. 1996.

54. LEVINE, R.S. Briefing paper: xylitol, caries and plaque. Br Dent J, London, v. 185, no. 1, p. 520, Nov. 1998

55. LIEBENBERG, W.H. Extended fissure sealants: an in adjunctive aid in the prevention of demineralization around orthodontic bands. Quintessence Int, [S.I.], v. 25, no. 5, p. 303-312, May 1994.

56. LUÍS, S. L. et al. Xilitol e flúor na prevenção da cárie dentária. Rev Port Estômato Med Dent Cirur Maxilofac, São Paulo, v. 42, n. 1, p. 35-39, jan./jun. 2001

57. MACHIULSKIENE, V: NYVAD, B : BAELUM, V Caries preventive effect of sugar-substituted chewing gum. Community Dent Oral Epidemiol, Copenhagen, v. 29, no. 4, p. 278-88, Aug. 2001.

58. MÄKINEN, K. K. et al. Conclusion and review of the "Michigan xylitol Programme" (1986-1995) for the prevention of dental caries. Int Dent J, London, v. 46, no. 1, p. 22-34, Feb. 1996.

59. MÄKINEN, K. K. et al. Comparison of erytrol and xylitol saliva stimulants in the control of dental plaque and mutans streptococci. Caries Res, Basel, v. 35, no. 2, p. 129-35, Mar./Apr. 2001

60. MATOS, M. S. Controle químico e mecânico de placa em pacientes ortodônticos: uma análise por grupo de dentes de acordo com o acessório ortodôntico empregado. R Dental Press Ortodon Ortop Facial, Maringá, v. 8, n. 1, p.87-93, jan./fev. 2003.

61. MATOS, M. S. de; VIANNA, M. I. P.; PITTA, A. Estudo comparativo entre a ação de higiene oral mecânica e controle químico com uma solução contendo flúor e clorexidina, sobre placa e gengivite em pacientes ortodônticos. Rev Aboprev, [S.I.], v. 4,n. 1,p. 29-38, jan./jun. 2001

62. MOREIRA, T. C.; SAMPAIO, R. K. P. L. Efeitos do tratamento ortodôntico sobre o esmalte: desmineralização e pigmentação.

R Dental Press Ortodon Ortop Facial, Maringá, v. 6, n. 2, p. 41-8, mar./abr. 2001.

63. MOTTA, R. G. da. Cimento de vidro ionomérico. In: Aplicações clínicas dos materiais dentários. Rio de Janeiro: Ed. de publicações científicas, 1991, cap. 19, p.137-140.

64. MOUTON, C.; SCHEININ, A.; MÄKINEN, K. K. Effect of a xilitol chewing gum on plaque quantity and quality. Acta Odontol Scand, Oslo, v. 33, no. 5, p. 251-257, Sept./Oct. 1975.

65. MUSSATO, S. I.; ROBERTO, I. C. Xilitol: edulcorante com efeitos benéficos para a saúde humana. Rev Bras Ciênc Farmacêuticas, v. 38, n. 4, p. 401-413, out./dez. 2002.

66. PEREIRA, A. C. Normas operacionais para execução de levantamentos em Odontologia In:___. Odontologia em saúde coletiva: planejando ações e promovendo saúde. Porto Alegre: Artmed, 2003. cap. 5, p. 83-116.

67. PINZAN, A. et al. Estudo comparativo de escovas dentais (convencionais e especiais) em pacientes com aparelho ortodôntico.
Ortodontia, São Paulo, v. 25, n. 3, p. 39-43, set./dez. 1992.

68. PINZAN, A. et al. Avaliação da efetividade de escovas dentárias bitufo com três diferentes diâmetros de cerdas, utilizadas por pacientes submetidos a tratamento ortodôntico fixo. Ortodontia, São Paulo, v. 28, n. 1, p. 61-7, jan./abr. 1995

69. RAMIRES, I. et al. Xilitol: perspectivas de uso em Odontologia. Rev Assoc Paul Cir Dent, São Paulo, v. 58, n. 1, p. 53-58, jan./fev. 2004.

70. REZENDE, C. L. D. et al. Influência da aparatologia ortodôntica na colonização microbiana das superfícies dentárias. R Dental Press Ortodon Ortop Facial, Maringá, v. 6, n. 2, p. 71-8, mar./ abr. 2001.

71. RIVERA, S.; CAVIERES, X. Efectos de los colutorios com clorhexidina al $0,1 \%$ y $0,2 \%$ en pacientes com tratamiento ortodoncio. Periodontia, Fortaleza, v. 7, n. 2, p. 74-77, maio/ago. 1998.

72. ROCCHI, V. A. A. P. et al. Eficiência do selante autopolimerizável. Rev Gaúcha Odontol, Porto Alegre, v. 37, n. 6, p. 475-479 nov./dez. 1989

73. ROSA, O. P. da S.; ROCHA, R. S. S. Clorexidina e cárie dentária Cecade News, [S.I.], v. 1, no. 1/2, p. 1-24, jan./ago.1993

74. SCHEININ, A. et al. Turku sugar studies XVIII incidence of dental caries in relation to 1-year consumption of xylitol chewing gum. Acta Odontol Scand, Oslo, v. 33, n. 5, p. 269-78, July/Aug. 1975

75. SCHEININ, A.; BÁNÓCZY, J. Xylitol and caries: the collaborative who oral disease preventive programme in Hungary. Int Dent $\mathbf{J}$ London, v. 35, no. 1, p. 50-57, 1985

76. SILVA, J. H. C. Avaliação clínica do Noplak em pacientes portadores de aparelhos ortodônticos fixos. Estudo Clínico Noplak, [S.I.], jan. 2002

77. SILVA FILHO, O. G. et al. Programa supervisionado de motivação e instrução de higiene e fisioterapia bucal em crianças com aparelho ortodôntico. Rev USP, São Paulo, v. 4, n. 1, p. 11-19, jan./mar. 1990.

78. SINTES, J. L. et al. Enhanced anticaries efficacy of a $0,243 \%$ sodium fluoride/ 10\% xylitol/ silica dentifrice: 3 year clinical results. Am J Dent, San Antonio, v. 8, no. 5, p. 231-235, Oct. 1995.

79. SMITS, M. T.; ARENDS, J. Influence of xylitol-and/or fluoride -containing toothpastes on the remineralization of surface softened enamel defects in vivo. Caries Res, Basel, v. 19, no. 6, p. 528-535, 1985.

80. SÖDERLING, E. et al. Influence of maternal xylitol consumption on acquisition of mutans streptococci by infants. J Dent Res Washington, D. C., v. 79, no. 3, p. 882-887, Mar. 2000

81. SOUZA, F. M. et al. Prevenção de cáries e doenças periodontais em Ortodontia corretiva: métodos simples para serem utilizados no consultório. Ortodontia, São Paulo, v. 27, n. 3 p. 87-94, set./dez. 1994.

82. TOOD, M. A. et al. Effect of o fluoride varnish on desmineralization adjacent to orthodontic brackets. Am J Orthod Dentofacial Orthop, St. Louis, v. 116, no. 2, p.159-167, Aug. 1999

83. TORTAMANO, A. et al. Avaliação da resistência à tração de agentes cimentantes para bráquetes ortodônticos. Rev Assoc Paul Cirur Dent, São Paulo, v. 56, n. 4, p. 259-63, jul./ago 2002.

84. WILTSHIRE, W.A. In vitro and vivo fluoride release from orthodontic elastomeric ligature ties. Am J Orthod Dentofacial Orthop, St. Louis, v. 115, no. 3, p. 288-292, Mar. 1999.

85. ZACHRISSON, S.; ZACHRISSON, B. U. Caries incidence oral higyene during orthodontic treatment. Scand J Dent Res, Copenhagen, v. 79, no. 6, p. 394-401, 1971

86. ZACHRISSON, S.; ZACHRISSON, B. U. Gingival condition associated with orthodontic treatment. Angle Orthod, Appleton, v. 42, no. 1, p. 26-34, Jan. 1972.

\section{Endereço para correspondência}

Fabíola Elias

Departamento de Odontologia da Universidade do

Sagrado Coração - Rua Irmã Arminda, 10-50 - Jd. Brasil

CEP: 17.011-160 - Bauru/SP

E-mail: bhielly@ig.com.br 